\title{
IMPROVING AIRCRAFT APPROACH OPERATIONS \\ TAKING INTO ACCOUNT NOISE AND FUEL CONSUMPTION
}

A. Rodríguez-Díaz, B. Adenso-Díaz, P.L. González-Torre

ARTÍCULO PUBLICADO EN LA REVISTA

Journal of Air Transport Management (2019), 77, 46-56

doi: https://doi.org/10.1016/j.jairtraman.2019.03.004

\begin{abstract}
While air transport brings very significant economic and social benefits to the cities and regions served by airports, aircraft noise is the single major cause of community opposition to airport operations, becoming a critical issue that affects the sustainability of future traffic growth. However, planning operations exclusively focusing on noise impact may result in an increase of fuel consumption or delays. This paper develops a suitable bi-objective model for landing aircraft, which finds a schedule that minimises noise impact, total fuel consumption and delays, under wake vortex separation and Constrained Position Shifting restrictions. The results of this model are compared with real operations in a major European airport to assess the potential level of improvements. By comparing with real data from Madrid-Barajas airport, the research shows potential improvements of up to $4.5 \%$ reduction of total fuel consumption (without increasing noise levels) only by modifying the sequence of arrivals, and up to $43 \%$ (without extra fuel consumption) of reduction in noise impact over the populations under study.
\end{abstract}

Keywords: air traffic management; noise impact; scheduling; wake vortex separation; aircraft fuel consumption. 


\section{INTRODUCTION}

By 2040, there will be a demand of $1.5 \mathrm{M}$ flights than can be accommodated, i.e. 160 million passengers unable to fly (Eurocontrol, 2018). Even with $1.5 \mathrm{M}$ flights unaccommodated and therefore lost, the network remains highly congested. Therefore, one of the central challenges facing the aviation industry is air traffic demand growth, which results in congestion in many airports, primarily hubs (Flores-Fillol, 2010). Managing take-offs and landings of any airport is a complex problem that plays an important role in Air Traffic Management (ATM). Runways and air controllers are limited resources, so air traffic needs to be planned carefully to limit peak demand and satisfy as many airlines' requirements as possible (Artiouchine et al., 2008).

Building new airports and expanding the runway capacity of existing ones is one possible solution to congestion. However, this solution might result in negative environmental impacts on the quality of life of near-airport communities, such as noise disturbance, emissions, water pollution and habitat destruction (Laurenzo, 2006; Ho-Huu et al., 2017; Arntzen and Simons, 2014; Visser et al., 2008). In fact, several studies show a correlation between aircraft noise exposure and cardiovascular or psychological disease (Postorino and Mantecchini, 2015).

During recent years, the population has increased in the cities and residential areas have become closer to airports, which implies an increase in the number of people affected by undesirable noise (Ganic et al., 2015a). Aircraft noise is a major cause of community opposition to current operations and to airport capacity improvement, becoming a critical issue that affects the sustainability of future traffic growth. Noise produced by aircraft has two main sources (Prats et al., 2009): aeronautical noise, which is the consequence of the friction of the air along the aircraft, and engine noise. 
During take-off, aircraft noise is mainly determined by the thrust of the engines required. Although take-off noise is significantly dominating noise issues around airports in terms of regulation and policies, due to engineer advances, higher noise reductions are expected at take-off operations, potentially increasing the importance of landing noise. Schäfer et al. (2019) found that lower fan pressure ratios and the absence of combustion noise leads to a $50 \%$ reduction in take-off noise. In contrast, during landing, the higher weight of allelectric aircraft will result in a $15 \%$ larger noise.

In an ideal world, an aircraft would take off, climb to its optimal cruising altitude, and maintain the cruising altitude if possible before beginning a constant, engines-idle descent until landing. In the real world, aircraft must coordinate with ATC which, when there are congestion delays, interrupts descents with level-offs and turns, forcing aircraft to spend more time at lower altitudes and deviate from their intended trajectory (Laurenzo, 2006). The initial schedule needs to be reorganised when planes are close enough to the airport, which means when they approach the TRACON - Terminal Radar Approach Control Facilities - between 5 and 50 miles from the airport (Inniss and Ball, 2004). The combination of low altitude and frequent thrust transients leads to significant aerodynamic noise impact during the arrival phase of the flight (Coppenbarger, 2007), created when the landing gear is deployed because aircraft use lower thrust.

Aircraft noise impacts on the environment significantly for several reasons (Jagniatinskisa et al., 2016): living areas are close to airport locations; operations during night time; flight noise events repeating periodically; and, compared to other transportation means, aircraft have large noise levels over the background noise. At many noise-sensitive airports, quieter aircraft are the key to minimising the impact of aircraft noise and ensuring a sustainable growth of airport capacity and air transport under increasing environmental constraints, for the benefit of the travelling individuals, airlines and their neighbouring 
communities (Eurocontrol, 2018).

The control of noise around airports is a complex matter because many different factors have a significant impact on the creation and propagation of noise (Ganic et al., 2015b): fleet mix (types of aircraft that are using the airport); shape and characteristics of arrival and departure procedures; airport characteristics (number of take-offs and landings, the distribution of traffic throughout the day and night, etc.); and airport location. Aircraft vary in performance regarding noise and emissions. Even two aircraft of the same type may behave differently, depending on their weight and the atmospheric conditions.

The main approaches addressed today to reduce noise impact in the surrounding communities of airports, excluding impact on land use and/or carrying noise insulation methods, consider operational procedures and regulatory restrictions (Rodriguez-Diaz et al., 2017b). Regarding airport procedures, operations are designed to serve the vast majority of aircraft under a wide range of weather and wind conditions, thus reducing the choices of aircraft with better capabilities to achieve better performance (Hebly and Visser, 2011). Regarding regulatory restrictions, the concern from authorities is expressed in terms of different legislations and official restrictions that have been imposed in many countries (Directive 2002/30/EC, 2002). Hence, minimising noise disturbance around airports is a task that needs the contribution of various stakeholders: institutions, aircraft manufacturers, airlines and air traffic control (ATC).

However, making the most efficient use of the current infrastructure by ATM would be the best alternative to balance demand with environmental restrictions. The challenge lies in simultaneously achieving safety, efficiency and equity, which are often competing objectives (Anagnostakis et al., 2001).

There are many factors that may oppose the objective of minimising noise (Christian and 
Sparrow, 2013): fuel burn, time-of-flight, emissions, etc. Hence, noise should not be the only parameter considered, as there are many stakeholders with various interests involved. Exclusively focusing on noise impact may result in an increase of fuel consumption (since avoiding noise impact on population located close to the airport may imply longer routes). To balance this conflict, the scope under research is to develop a suitable model for landing aircraft that finds a schedule that minimises noise impact, total fuel consumption and delays, while making the most of the current capacity of the runways.

Moreover, in this paper we aim to prove that there is a margin for improvement in terms of noise reduction and fuel consumption, just by deciding on the most appropriate landing runway and order in the landing sequence. Here we are not considering introducing any change in the Standard Terminal Arrival Routes (STAR) of the considered airport since in the actual procedures there is still a place for considering noise impact and aiming for an efficient schedule. Our decision process starts in the approaching routes, and it is valid and applicable in general when the airport have more than one approach route, independently of the STARs involved.

The paper is organized as follows: Section 2 describes the problem of the runway bottleneck and environmental concerns, and describes different approaches that have been studied in this field. In Section 3, the proposed linear model is presented, as well as the decision variables considered used to design the model. Also, as part of the methodology, the real scenario used for testing real operations is introduced, as well as the optimization methodology. Section 4 presents a detailed example with a limited number of flight plans to show how the model works. In Section 5 the numerical results in the real environment of the Adolfo Suárez Madrid-Barajas airport are described and analyzed. Finally, a short summary is given in Section 6, together with suggested topics 
for future research in this area.

\section{PREVIOUS APPROACHES}

Bennell et al. (2013) undertook an extensive review of optimizing algorithms for scheduling flights in airports; however noise restrictions are almost not considered in the development of these algorithms. Only Hebly and Visser (2011) have studied the effects of taking into account noise measured in one point, which implies a delay driven support tool for sequencing and scheduling, under the formulation of an MILP (Mixed Integer Linear Programming) problem, where the sequencing is based on the principle of constraint position shifting (CPS). Based on the results of their model, and using the concept of fixed arrival routes, a small improvement in noise exposure in the point under study could be achieved.

As far as we know, the only optimization algorithm for landing scheduling that considers noise impact is the one just mentioned. However, some other studies deal with the design of optimal routes that reduce the negative impact of aircraft noise on people living in the vicinity of airports. Prats et al. (2009) resolved a non-linear multi-objective optimal control problem to find the best trajectory for a given scenario, aircraft and time. Khardi (2014) presented a dynamic method to provide optimal paths that minimise aircraft impacts and fuel consumption, assessing a two-segment approach as an optimal trajectory. Ho-Huu et al. (2017) formulated a bi-objective optimisation problem by also considering noise and fuel as objectives to design optimal environmental routes. They consider the percentage of awakening to measure noise impact and present a novel application of MOEA/D (multi-objective evolutionary algorithm based on decomposition) for designing new noise abatement departure routes.

The model defined in this study calculates the most suitable landing runway and the 
landing times that minimize noise for the surrounding population, fuel consumption and delay. To minimize delays and fuel consumption, the CPS approach has been considered in our research. The CPS approach is based on a fundamental underlying principle that involves the specification of a parameter that limits the maximum number of position shifts (forward or rearward) that any aircraft will receive with respect to its first-come, first-served (FCFS) position (Dear, 1976; Rodriguez-Diaz et al., 2017a). Previous studies in the literature have dealt with scheduling considering noise, fuel burn, WTC or CPS as constraints, not as part of the objective function. This paper deals with all of them at the same time. Moreover, this paper develops a model that could be used in real operations and implemented in real software, given its low computational burden.

The model developed here, not only aims to optimize runway capacity as in RodriguezDiaz et al. (2017a) but also to optimize fuel consumption of the flights considered. One of the decisions taken consists of choosing the landing runway that minimizes the noise impact of the final approach route for the surrounding population without proposing any change in the existing approach routes and operational procedures of the airport. A linear model is defined to cope with the bi-objective nature of the problem (minimize total noise impact and minimize total fuel consumption), and the $\varepsilon$-constraints method is used to explore the Pareto frontier. As mentioned, these optimal decisions are being tested against a real operation in a major European airport, by measuring potential improvement in cost and noise level.

\section{PROPOSED APPROACH AND METHODOLOGY}

To analyze the problem and test the potential improvement in real operations, we will consider a set of instances consisting of a sequence of flights approaching an airport with 
various landing runways subject to CPS. As one of the aims of the sequencing is to avoid a result that produces excessive amounts of noise in the surroundings, it is necessary to select a metric to measure the impact of the noise on landing aircraft for each assessed alternative. An aggregate metric called LOUDPeople, LP (Christian and Sparrow, 2013), is considered suitable for our purpose. The result from this metric avoids that we might make the determination of assigning an unacceptably high noise level to a small population in order to reduce the impact of the noise on many citizens:

$$
\begin{aligned}
& L P=\sum_{i} \text { Population }_{i} * 2^{\left(\frac{S E L_{i}-100}{10}\right)} \\
& S E L=L_{e q}+10 * \log _{10}(T)
\end{aligned}
$$

where $i$ represents each village in the surroundings; $\mathrm{SEL}_{i}$ is the Sound Exposure Level (in $\mathrm{dB}$ ) normalised to one second at village $i$; $\mathrm{T}$ is the duration in seconds of the time period considered to measure the noise; and $L_{e q}$ is the equivalent sound level measured at each village. Note that when $\mathrm{T}=1$ (as will happen in our study), it is $S E L=L_{e q}$.

Once we defined how to assess the noise impact, a linear model was defined to cope with the bi-objective nature of the problem (minimise total noise impact and minimise total fuel consumption). The data needed are:

$$
\begin{array}{ll}
\mathrm{N} & \text { Total number of flight plans (flights) considered } \\
\mathrm{R} & \text { Number of approach routes in the airport under study } \\
\mathrm{HS}_{i} & \text { Scheduled take-off time of flight } i \text { from departure airport } \\
\text { flight_time } i, r & \text { Minimum flight time of flight } i \text { when using route } r \\
\mathrm{~K}_{i} & \text { Consumption of fuel per second of flight } i \\
L P_{i r} & \text { Noise impact of flight } i \text { in route } r \text { for a certain population }
\end{array}
$$


CPS Constrained Position Shifting. For CPS $=0$, the order of flights is the initial one $(1,2, . ., \mathrm{N})$

WTC $_{i, j} \quad$ Wake Turbulence Category separation between flight plan $i$ and $j$.

A big number (classically used for modelling convenience).

The decision variables considered to define a feasible schedule are:

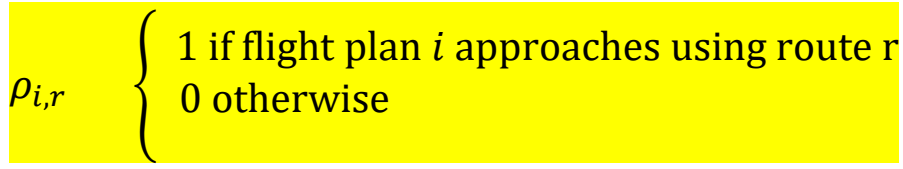

$\mathrm{t}_{i} \quad$ Landing time of flight plan $i$ as scheduled by the model

$\mathrm{d}_{i} \quad$ Forced delay to flight plan $i$ before landing, in order to assure safety separation distance between consecutive flight plans (minutes)

$\tau_{i, j} \quad\left\{\begin{array}{l}1 \text { if flight plan } i \text { lands before } j\left(t_{j}>t_{i}\right) \\ 0 \text { otherwise }\end{array}\right.$

With this notation the objective functions are:

- Minimize total fuel consumption:

$$
\min \sum_{i}\left(t_{i}-H S_{i}\right) \times K_{i}
$$

- Minimize total noise impact:

$$
\min \sum_{i} \sum_{r}\left(L P_{i, r} \rho_{i, r}\right)
$$

To ensure that the solutions obtained are feasible, the following constraints are introduced:

1) Each flight plan $i$ is only assigned to one route. Therefore for each flight $i$, exactly one $\rho_{i, r}$ is 1 :

$$
\sum_{r} \rho_{i, r}=1 \quad \forall i
$$


2) The real time of the arrival of flight plan $i$ is determined by its departure time plus the flight time of the selected route and can have a delay so as to respect WTC separation restrictions (only the current route $r$ must be considered in the calculation, identified because $\rho_{i, r}=1$ ):

$$
t_{i}=d_{i}+\sum_{r}\left(H S_{i}+\text { flight_time }_{i, r}\right) \times \rho_{i, r} \quad \forall i
$$

3) Either flight plan $i$ lands before $j$ or flight plan $j$ lands before $i$ :

$$
\tau_{i, j}+\tau_{j, i}=1 \quad \forall i, j ; j \neq i
$$

4) Separation constraints between flight plan $i$ and flight plan $j$ in the landing runway are guaranteed (in this inequation, if $\tau_{i, j}=1$ remains $t_{j} \geq t_{i}+W T C_{i, j}$ and the separation between flight $\mathrm{i}$ and $\mathrm{j}$ is at least WTC as required; else, if $\tau_{i, j}=0$ it remains $t_{j} \geq t_{i}+W T C_{i, j}-M$ being $\mathrm{M}$ a big number and therefore the constraint becomes superfluous):

$$
t_{j} \geq t_{i}+W T C_{i, j}-M\left(1-\tau_{i, j}\right) \quad \forall i, \forall j \neq i
$$

5) CPS constraint in landing is fulfilled (flight $i$ must land in positions $i \pm C P S$ ):

$$
\begin{aligned}
& \sum_{j \neq i} \tau_{i, j} \geq N-(i+C P S) \quad \forall i \\
& \sum_{j \neq i} \tau_{i, j} \leq N-(i-C P S) \quad \forall i
\end{aligned}
$$

\subsection{Finding the set of Pareto efficient solutions}

The design of a system with more than one objective is referred to in the literature as a Multiple Criteria Decision Making problem (Miettinen, 2008). This type of decision and planning problems involves multiple conflicting objectives that need to be considered simultaneously. 
Solving a Multi-Objective Optimisation problem does not lead to a single global solution.

Due to the competing nature of the objectives, it might be possible to obtain an infinite number of solutions where each unique solution assigns different priorities to the problem objectives. These solutions are known as Pareto points and constitute the so called Pareto frontier. For instance, in our case with two objectives, the set of non-dominated solutions (Pareto frontier) is defined in such a way that for each point, minimising the global fuel consumption cannot be improved without sacrificing noise impact.

The generation of the Pareto frontier can be accomplished through scalarisation or vectorisation methods (Chircop and Zammit-Mangion, 2013): scalarisation methods convert the Multi-Objective Optimisation problem into various parametric SingleObjective Optimisation problems; vectorisation methods tackle the Multi-Objective Optimisation problem directly. The first ones typically define a set of differently parameterised single-objective models and apply multiple runs of a single-objective optimiser. Laumanns et al. (2006) states that it is a difficult and sometimes impossible task to choose a sequence of parameter values, such that the whole Pareto front is discovered because the choice of the parameter values determines which specific elements of the Pareto set are found.

One of the most popular methods to generate the Pareto front is the $\varepsilon$-constraint method (Haimes et al., 1971). Its logic works by choosing one objective function as the only objective and the remaining objective functions as constraints; by a systematic modification of the constraint bounds, different elements of the Pareto frontier are obtained. The method relies on the availability of a procedure to solve constrained singleobjective problems.

Algorithm in Figure 1 gives an implementation of the method (Chankong and Haimes, 
1983) for the case of two objectives. The idea, as stated before, is to iteratively increase the constraint bound by a pre-defined constant $\delta$. The necessity to choose such a value represents also the main drawback of this approach. Since only one solution can be found in each interval, the discretisation must be sufficiently fine not to "miss" substantial Pareto-optimal solutions. In the worst case, the difference between objective vectors might be as small as the machine accuracy of the computer used to run the algorithm.

FIG. 1

In our case, the following specific procedure was used:

- Minimise only the global consumption, which indicates the superior limit of total noise impact (point on the far right in our frontiers).

- Minimise only the total noise impact (point on the far left).

- Solve the model being the objective function the minimisation of the global fuel consumption, but adding a new constraint that limits the total noise impact according to some $\varepsilon$ proportions $([1 ; 0.95 ; 0.90 ; \ldots ; 0])$, in the segment of the noise range defined by steps 1 and 2 .

\subsection{Scenario description}

To test the capabilities and efficiencies of our model and analyse the results, we will consider a real scenario with data from arrivals at Adolfo Suárez Madrid-Barajas Airport, which is the biggest airport in Spain and ranks 5th in the EU in terms of passengers 
(AENA, 2018). This airport operates in two different configurations that determine the direction of departures and arrivals. In the North configuration, which is the preferred one (Eurocontrol - Public Airport Corner, 2018), airplanes take off and land, heading north. In the South configuration, airplanes take off and land, heading south.

Adolfo Suárez Madrid-Barajas Airport has four runways, composed of two parallel runways on a north-south axis separated by $1.8 \mathrm{~km}$, and another two parallel runways on a northwest-southeast axis separated by $2.5 \mathrm{~km}$. Depending on the configuration, the runways have different denominations (Figure 2 shows the layout of the runways and their names in both configurations). In this way, in the North configuration, aircraft take off using runways 36L and 36R (left and right respectively) and land using runways 32L and $32 \mathrm{R}$.

FIG. 2

Adolfo Suárez Madrid-Barajas Airport has various correctives to reduce noise levels in compliance with European Directive 2002/30/EC, such as the prohibition of night-time operations of aircraft with noise levels of four or higher (according to EASA scale), and operating restrictions due to noise quota from 23:00 to 07:00 local time.

To collect noise information for our experiments, the WebTrack tool of the Spanish National Airports Agency (AENA) has been used. WebTrack allows for checking noise levels caused by different aircraft by using the trajectory of the airplane in the surroundings of the airport, both for landings and arrivals (Figure 3 shows a screenshot of this tool). This function is accomplished thanks to the data provided by the noise monitoring system SIRMA [“Sistema Integral de Ruido de Madrid-Barajas”] (SIRMA, 2018). This system receives information on both the noise recorded at the 27 Noise Monitoring Terminals (NMTs) installed around the airport, as well as radar and flight 
plan data from the SACTA system ("Sistema Automatizado de Control de Tránsito Aéreo"). The WebTrack tool provides information about the aircraft (flight number, approach route and altitude) and associates these data with the corresponding aircraft's noise emission level for each NMT, which is necessary for feeding our model.

FIG. 3

\section{TABLE 1}

Table 1 details the location of the 27 NMTs, average noise of each NMT for 2017 caused by aircraft, the population of each affected village and whether this NMT noise measure corresponds to landings or departures, taking as a reference the North configuration (the preferred one). Analysing Table 1 , out of 27 , only seven reflect the noise produced by arriving aircraft (which is what we are analysing). The biggest population of these seven locations is in Torrejón (NMT 20), and the locations with the worst records of noise measures are Coslada (NMT 11) and San Fernando de Henares (NMT 10). Considering the North configuration, Coslada and San Fernando de Henares are the NMTs that register the worst noise records because they are under the final approach route of aircraft landing on runway 32L.

Also, since the objective of this study is not only to reduce the noise impact on the populations with higher noise records but also to consider the overall population impacted on, we will also take into account the NMT of Torrejón de Ardoz since this population is closer to the final approach route of aircraft landing on runway 32R. Although the noise records are not as severe as those for Coslada and San Fernando, the population impacted on is more than double that of Coslada and San Fernando. This allows us to have a representative and balanced measure of global noise impact on the surrounding areas of both landing runways. So, for our research, these three NMTs will be considered for 
measuring noise impact and gathering individual noise impacts with the WebTrack tool, as the other NMTs reflect a smaller noise impact.

In our paper, noise estimation is based on single events modelled by AENA following ISO 20906:2009, and a metric that allows us to use these real data gathered by the NMTs, thus obtaining the noise disturbance in the affected population. Another possibility would have been using noise contours maps, which are a graphical representation of the significant levels of noise in a given territory, obtained by measuring a set of representative points, over different periods. Although in different occasions they were used in the airports neighborhoods (ICAO, 2008; FAA, 2013), and are widely used for legislation purposes, noise assessment and study of noise effects in the population, however they are not so frequently employed in the literature for scheduling optimization purposes (Tian et al., 2018); Kim et al., 2018).

Noise data was chosen for a full day that Adolfo Suárez Madrid-Barajas Airport operated using the North configuration, i.e. 20th January 2018. Timetables for each flight plan were collected using an online flight tracker (FlightRadar24, 2018).

The following assumptions were made in our experiments:

- Noise over San Fernando de Henares, Coslada and Torrejón de Ardoz was taken when all the aircraft were overflying the corresponding NMT sensors of these populations

- Average noise produced by each type of aircraft was determined for each runway to calculate the alternative noise caused by the aircraft if landing on the alternative runway (Table 2). The use of generic aircraft types has been validated by Torija and Self (2018) for computing aviation noise outputs. 
- Fuel consumption data for the whole flight are average data per aircraft extracted of ICAO Carbon Emissions Calculator Methodology document (ICAO Carbon Emissions Calculator Methodology, 2016). This is a proxy of the real consumption data.

- Aircraft landing at the $32 \mathrm{R}$ runway take five minutes more approach time than those landing on the $32 \mathrm{~L}$ runway.

- Wake vortex minimum separation considered is the one established by document 4444 of OACI.

- Given the bi-criteria nature of the model, the $\varepsilon$-constraints methodology is used to find the Pareto frontier for each instance.

All the computational experiments are done considering different time slots, different CPS and the real flight time of each flight. The optimization software used to solve the models is LINGO v17.

\section{A FIRST EXAMPLE OF THE MODEL SOLUTION}

For a better understanding of the model and the study framework, a detailed example of just five flight plans that landed in Adolfo Suárez Madrid-Barajas Airport on 20th January 2018 is first presented. Details of those flights are provided in Table 3.

TABLE 3

Considering CPS $=2$ (i.e., each flight can only shift at most two positions in relation to its original position in the sequence); we ran the model, forcing five different maximum noise levels to find five points in the Pareto frontier. Figure 4 shows the result given by 
the model compared to the real solution. The diamond points represent solutions found by our model in the Pareto frontier, and for each point, the sequence and landing runway of each flight plan are specified. The square point reflects the real solution (what actually happened that day) and the sequence of landings, and the runways where the flights landed.

FIG. 4

It can be seen that both the landing runways and the sequence of landings chosen by the model change depending on the point of the Pareto frontier. When the model calculates the best solution to minimise total fuel consumption (i.e., not limiting at all the noise level, thus finding the point in the far right in Figure 4), it proposes that the aircraft consuming the most in the sequence, lands as early as possible considering the CPS restriction imposed. This means for flight QR149 (FP5), which in the real sequence lands in the fifth position, the model proposes it to land in the third position. However, when the model calculates the best solution to minimise total noise impact, it can be seen that it chooses the 32L runway for all the flights in the example, as this runway and its approach route is the one that minimises the population disturbed by the noise generated by lading aircrafts. It can be seen that the CPS does not have an impact on the result when minimising the total noise impact, since the model chooses the same order as the initial sequence (when minimising noise, only the election of the most appropriate landing runway is taken into account for this objective).

Comparing the total real fuel consumption with the best solution found by the model in this small example, our model is able to reduce almost $2 \%$ of total fuel consumption (more than 1 ton of fuel of the total consumption of the flights considered in this instance), only by changing the order of the landing sequence. If the same analysis is performed in terms 
of total noise impact, the result is that more than a $30 \%$ total noise impact reduction is achieved.

\section{RESULTS AND DISCUSSION}

To evaluate the influence of the value of CPS, a first set of data has been computed, considering different values of CPS: from the lower value CPS $=0$ (i.e., the sequence of landings in the same order as the real one, FIFO), to CPS $=5$ (Rodriguez-Diaz et al. 2017a, noted that controllers always wish to keep the sequence as similar as possible to the FCFS sequence received, and the limit of 5 was defined in their study). As always occurs when relaxing constraints in optimization models, results for CPS $=5$ are no worse than for CPS $=0$ in terms of total fuel consumption $(\mathrm{kg})$, achieving a total reduction of 2,000 $\mathrm{kg}$ for the best case of CPS $=0$ vs. the best for CPS $=5$ (see Figure 5). When compared to the real sequence, the improvements are almost $20,000 \mathrm{~kg}$ of total fuel reduction. For the other values of CPS, the results are always between the bounds of the solution found for CPS $=0$ and CPS $=5$. Therefore, the next set of experiments were performed, considering only these two extreme values for CPS.

FIG. 5

To select the time frames of data used to analyse and compare the results after running the defined model, we study how congestion can influence the results and the possible improvements found by the model. Congestion is determined by the total number of landing aircraft per period. Figure 6 shows the number of airplanes that landed in every hour period at Adolfo Suárez Madrid-Barajas Airport the day of the data set. 
FIG. 6

As can be seen, between 8:00 - 9:00 and 12:00 - 13:00 are peak periods, while during the night, the number of landing aircraft is significantly smaller. Taking into account that the number of flights in each sample need to be equal for comparison purposes (50 flight plans in this case), the chosen periods for our analysis are:

- Low congestion - [00:00 - 8:00]

- High congestion - [12:00 - 13:30]

- Intermediate congestion - [20:10 - 22:10].

Figure 7 to Figure 9 show the results of different sets of data, depending on the time of day considered. As can be seen, for all three cases, all the solutions found by the model are better than the real operation, dominating (i.e., being better in cost and noise simultaneously) the real schedules of that day. As noted before, the best solutions are obviously found for CPS $=5$.

FIGS. 7, 8 \& 9

If we evaluate in these three figures the opportunities for cost reduction when relaxing the CPS constraint (i.e., allowing CPS $=5$ instead of CPS $=0$ ) we observe in the right extreme points of the figure (this means, points that minimize just fuel consumption), that in the Low congestion case we find a solution which allows to save $0.25 \%$ of total fuel, in the High congestion case $0.49 \%$, while in the Intermediate congestion case the reduction in fuel consumption goes up to $1.17 \%$.

Given that the three real operation points are dominated by all the points in the three Pareto frontiers, we can analyse the results in terms of the potential percentage of improvement in total fuel consumption and total noise impact, comparing the real 
situation with the best solution regarding noise (extreme left point in the frontier) and cost (extreme right point; see Table 4). It can be seen that the best results, in terms of total fuel consumption improvement, are again achieved for the scenario with Intermediate congestion (for both CPS).

These results indicate that when congestion is very low or very high, aircraft arrive at the airport with higher spacing or very close respectively, and the gain of applying CPS is very low. However, when the gaps between aircraft are big enough to combine different aircraft optimising the WTC but not very high so that the order of the aircraft is not altered without producing large waiting periods (impacting on fuel consumption), the improvement achieved by applying the CPS method is higher. We must point out here that the low percentage of improvement must be analysed, considering that the approach and landing procedures represent only a small percentage of the total flight time.

TABLE 4

Regarding the results for noise improvement, it can be seen that CPS has no impact on the solutions achieved, with improvements in respect to the real noise impact much higher than in the cost case (more than 35\% in all the scenarios considered). Allowing the model to select the most appropriate landing runway in terms of noise, confirms that there is place for improvement and can lead to important reductions in terms of noise impact over the populations that surround this airport.

After this analysis, we can state that noise and fuel-burnt reduction is achieved in our model as a consequence of 2 factors:

- Selecting the most appropriate landing runway allows the model to achieve reductions of overall noise in the population surrounding the airport. 
- Changing the sequence of arrival allows the model to reduce the total fuel consumption since it leads to reductions in the spacing between aircrafts, reducing flight-times and selecting the optimal sequence of arrival.

With our bi-objective model we achieve solutions that, at the same time, are optimized in both objectives (fuel and noise), finding schedules which are much better than real operation.

Having observed the potential for improvement in both noise and fuel consumption, it could be interesting to test how the type of aircraft influences the potential improvements. Figures 10 and 11 show the difference between the real operation and the two best alternatives for both criteria (i.e., the difference in fuel consumption and noise impact between the real data and the best solution found when minimising fuel consumption, and the best solution found by the algorithm when minimising the noise impact for the testbed of intermediate congestion).

FIGS. $10 \& 11$

Figure 10 shows that when minimising fuel consumption, Airbus 332 has an average improvement of $450 \mathrm{~kg}$ when CPS $=5$ (which is a $0.39 \%$ of its total consumption) while for CPS $=0$ the fuel average saving is $150 \mathrm{~kg}(0.14 \%$ of its total consumption). It is reasonable to observe that the biggest improvements are for highest CPS due to higher improvement margins. It is also interesting to note that the largest percentages of total fuel reduction, in comparison with the total amount of fuel consumption per aircraft, are for AT75, A319 and B38M.

Figure 11 shows that when minimising noise impact, Airbus 319 has an average improvement of $\mathrm{LP}=14000$ for both $\mathrm{CPS}=5$ or $\mathrm{CPS}=0$, which contributes to a reduction 
of $18 \%$ in the noise impact of this aircraft in the surrounding populations. For Airbus 333 or Boeing 788, the model can achieve reductions of around $50 \%$ of noise impact in the populations affected by the final approach route.

\section{CONCLUSIONS}

In this paper a suitable bi-objective model for scheduling the landing of a sequence of aircraft by minimising noise impact and total fuel consumption (while limiting delays and maximising runway capacity) is presented. The model makes the most of the current capacity of the runways by choosing the most appropriate landing runway and landing time under wake vortex separation and CPS restrictions. It is also important to note that the proposed approach does not imply any change in the STARs or the operational procedures of the considered airport.

By using this model, we tested the potential improvements that are possible to attain when comparing current operational routines with the best alternative found by the model. The scenario considered in order to validate the proposed approach real data of landing aircraft at the Adolfo Suárez Madrid-Barajas Airport.

By analysing real flight plans on a specific day, improvements of up to $4.5 \%$ of total fuel consumption reduction were found, by modifying only the order of the approach sequence of arrivals at the airport, and up to $43 \%$ of reduction in total noise impact, which confirms that scheduling can be easily improved and have an immediate positive impact on the surrounding population of the airport without incurring delays and harming fuel consumption. Aircraft with the worst records of noise are those that have the highest possibilities of improvement, and aircraft that have lower consumption are those with lower absolute values of fuel reduction in $\mathrm{kg}$ but higher relative reductions in comparison 
to the total fuel consumed by the flight.

Lastly, it is important to note that congestion (total number of landing aircraft per time period) has an important effect on the possibilities of improvement of this model. Although for all three cases with different flight densities, all the points found by the model are better than the real operation, and dominating (i.e., being better with regard to cost and noise simultaneously) all of those in the current operation, the best results in terms of total fuel consumption improvement are achieved for the scenario with Intermediate congestion. Hence, being able to smooth the traffic over peak hours could have rewarding results; opening the door to achieving improvements in terms of having wider scheduling options that take into account noise reduction and fuel consumption as objectives.

Regarding the practical application of the model, while the route segment of the filed flight plan does not usually change during the flight itself, the STAR, the approach route and the runway might change depending on the weather conditions (such as wind), and air traffic congestion around the airport, among other factors. This is why the filled flight plan route ends not at the destination airport but at the point where a STAR begins, since the STAR, approach route and landing runway are usually assigned to the pilot during the en-route phase of the flight. Since the computational time of our model is very low, our model can be run during this phase to support the air traffic controllers on the best approach route that needs to be selected in order to balance noise disturbance in nearby populations and total fuel consumption. Note that the complete Pareto frontier would not be needed for real implementation as it was only used for our experiments, which reduces even more the computational time and would allow air traffic management systems to run periodically the model with the last updated data in order to find continuously the best solution. 
There are a number of topics open for further research. Depending on the availability of more accurate real-time atmospheric condition information, a more accurate noise prediction could be obtained. This would allow for adjusting the decisions taken by the model with respect to noise propagation properties and noise impact influence on surrounding populations of the proposed solution. Also, extending the problem to consider all the flight trajectories would allow us to have a wider vision of the problem. Finally, the possibility of considering as an objective not only the total reduction but also the priority of flights would be interesting to explore. 


\section{REFERENCES}

AENA (2018). http://www.aena.es/en/corporate/main-annual-data.html (last accessed: $28^{\text {th }}$ October 2018).

Anagnostakis, I., Clarke, J.P., Böhme, D., Völckers, U. (2001). "Runway operations planning and control: Sequencing and scheduling", Journal of Aircraft, vol. 38, no. 6, pp. 988-996.

Arntzen, M., Simons, D.G. (2014). "Modeling and synthesis of aircraft flyover noise". Applied Acoustics, vol. 84, no. 1, pp. 99-106.

Artiouchine, K., Baptiste, P., Dürr, C. (2008). "Runway sequencing with holding patterns", European Journal of Operational Research, vol. 189, pp. 1254-1266.

Bennell, J. A., Mesgarpour, M., Potts, C. N. (2013). “Airport runway scheduling”. Annals of Operations Research., vol. 204, no. 1, pp. 249-270.

Chankong, V., Haimes, Y. (1983). Multiobjective decision making: theory and methodology. Dover Publications, Mineola, New York.

Chircop, K., Zammit-Mangion, D. (2013). “On Epsilon-Constraint Based Methods for the Generation of Pareto Frontiers". Journal of Mechanics Engineering and Automation, vol. 3, pp. 279-289.

Christian, A.W., Sparrow V.W. (2013). “A multi-objective evolutionary optimization approach to procedural flight-noise mitigation". Proceedings of Meetings on Acoustics, vol. 19, 040073. https://doi.org/10.1121/1.4799982

Coppenbarger, R. (2007). Oceanic tailored arrivals. In: Boeing Tailored Arrivals Symposium, Seattle, WA.

Dear, R.G. (1976). "The dynamic scheduling of aircraft in the near terminal area: technical report". Cambridge, MA: Flight Transportation Laboratory, Massachusetts. Institute of Technology.

Directive 2002/30/EC (2002). Directive 2002/30/EC of 26 March 2002 of the European Parliament and of the Council. https://eur-lex.europa.eu/legalcontent/EN/TXT/?uri=celex\%3A32002L0030 (last accessed: $28^{\text {th }}$ October 2018). 
Document 4444, OACI. "ATM, Procedures for Navigation Services - Air Traffic Management".

https://www.icao.int/SAM/Documents/2010/ASTERIX/07\%20\%20DOC4444.pdf

(last accessed: $28^{\text {th }}$ October 2018).

Eurocontrol (2018). "European Aviation in 2040 - Challenges of Growth". https://www.eurocontrol.int/articles/challenges-growth (last accessed: $28^{\text {th }}$ October 2018).

Eurocontrol - $\quad$ Public Airport Corner (2018). https://ext.eurocontrol.int/airport_corner_public/LEMD (last accessed: $28^{\text {th }}$ October 2018).

FAA (2013). "Integrated Noise Model (INM). Computer model to evaluate the aircraft noise impacts in the vicinity of airports. Federal Aviation Administration (FAA) 7.0d ed". FlightRadar24 (2018). www.flightradar24.com (last enquiry: $7^{\text {th }}$ March 2018).

Flores-Fillol, R. (2010). “Congested hubs”. Transportation Research-B. vol. 44, pp. 358370.

Ganic, E., Dobrota, M., Babic, O. (2015a). “Analysis of noise abatement measures on European airports". Applied Acoustics, vol. 92, pp. 115-123.

Ganic, E.M., Netjasov, F., Babic, O. (2015b). "Implementing noise abatement measures on airports: statistical analysis of the influential factors". Mircea cel Batran Naval Academy Scientific Bulleting, vol. 18, pp. 251-260.

Haimes, Y.V., Lasdon, L.S., Wismer, D.A. (1971). "On a bicriterion formation of the problems of integrated system identification and system optimization". IEEE Transactions on Systems, Man and Cybernetics, vol. SMC-1, no. 3, pp. 296-297.

Hebly, S.J., Visser, H.G. (2011). “Air Traffic Control Decision Support for Integrated Community Noise Management”. Aeronautics and Astronautics, vol. 1, pp. 532-548.

Ho-Huu, V., Hartjes, S., Visser, H.G., Curran, R. (2017). “An Efficient Application of the MOEA/D Algorithm for Designing Noise Abatement Departure Trajectories", 
Aerospace - Open Access Aeronautics and Astronautics Journal, vol. 4, no. 4, pp. 5469. doi: $10.5772 / 25215$

ICAO (2008). “Environmental protection. Aircraft noise. International Civil Aviation Organization (ICAO), Annex 16 to the Convention on International Civil Aviation".

ICAO (2016). “Carbon Emissions Calculator Methodology. Version 9 June 2016”.

INE, Instituto Nacional de Estadística. www.ine.es. (last enquiry: $7^{\text {th }}$ July 2018).

Inniss, T., Ball, M.O. (2004). "Estimating one-parameter airport arrival capacity distribution for air traffic flow management", Air Traffic Control Quarterly, vol. 12, no. 3, pp. 223-251.

Jagniatinskisa, A., Fiksa, B., Zaporozhetsb, O., van Oostenc, N. (2016). “Annual noise assessment in the vicinity of airports with different flights' intensity", Applied Acoustics, vol. 101, pp. 168-178.

Khardi, S. (2014). "Environmental impact reduction of commercial aircraft around airports. Less noise and less fuel consumption", European Transport Research Review, vol. 6, pp. 71-84.

Kim, J., Dongwook, L., Monteiro, D.J., Kirby, M., Mavris, D. (2018). “Multi-objective Optimization of Departure Procedures at Gimpo International Airport", International Journal of Aeronautical and Space Sciences, vol. 19, no. 2, pp. 534-541.

Laumanns, M., Thiele, L., Zitzler, E. (2006). “An efficient, adaptive parameter variation scheme for metaheuristics based on the epsilon-constraint method", European Journal of Operational Research, vol. 169, no. 3, pp. 932-942.

Laurenzo, R. (2006). "Hushing the roar of air traffic growth". Aerospace America, vol. 1, pp. 38-42.

Miettinen, K. (2008). "Introduction to Multiobjective Optimization: Noninteractive Approaches". Multiobjective Optimization. Lecture Notes in Computer Science, vol. 252. Springer, Berlin, Heidelberg. https://doi.org/10.1007/978-3-540-88908-3_1. 
Postorino, M.N., Mantecchini, L. (2016). "A systematic approach to assess the effectiveness of airport noise mitigation strategies". Journal of Air Transport Management, vol.50, pp.71-82.

Prats, X., Quevedo, J., Puig, V. (2009). "Trajectory Management for Aircraft Noise Mitigation”. ENRI International Workshop on ATM/CNS. Tokyo, Japan.

Resolution of 30 August 2006 of The Spanish Civil Aviation Authority.

Rodríguez-Díaz, A., Adenso-Díaz, B., González-Torre, P.L. (2017a). "Minimizing deviation from scheduled times in a single mixed-operation runway", Computers and Operations Research, vol. 78, pp. 193-202.

Rodríguez-Díaz, A., Adenso-Díaz, B., González-Torre, P.L. (2017b). "A review of the impact of noise restrictions at airports", Transportation Research Part D, vol. 50, pp. 144-153.

Royal Decree 1257/2003 of 3 October. https://www.fomento.gob.es/recursos_mfom/pdf/65989BC7-CF9C-4876-9774-

F8B16C1EC8E3/96583/RD1257_2004.pdf (last accessed: 28 ${ }^{\text {th }}$ October 2018).

SIRMA (2018). http://www.aena.es/en/madrid-barajas-airport/sirma-map-terminals.html (last accessed: $28^{\text {th }}$ October 2018).

Schäfer, A.W., Barrett, S. R. H., Doyme, K., Dray, L. M., Gnadt, A. R., Self, R., O’Sullivan, A., Synodinos, A.P., Torija, A.J. (2019). "Technological, economic and environmental prospects of all-electric aircraft”, Nature Energy, vol. 4, pp.160 - 166.

Tian, Y., Wan, L., Hana, K., Ye, B. (2018). “Optimization of terminal airspace operation with environmental considerations", Transportation Research Part D, vol. 63, pp. 872889. https://doi.org/10.1016/j.trd.2018.06.018

Torija, A.J., Self, R. (2018). "Aircraft classification for efficient modelling of environmental noise impact of aviation", Journal of Air Transport Management, vol. 67, pp. 157-168. 
Visser, H., Hebly, S., Wijnen, R. (2008). "Improving the management of the environmental impact of airport operations". New Transportation Research Progress, chapter 1, pp. 1-65, Nova Science Publishers.

WebTrack AENA. http://www.aena.es/en/madrid-barajas-airport/interactive-noisemap.html (last accessed: $28^{\text {th }}$ October 2018). 
Input: Objective bounds $f$ and $\bar{f} \in \mathrm{R}$, and increment $\delta \in R$ $\mathrm{P}:=\varnothing$

$\varepsilon:=\bar{f}$

while $\varepsilon \geqslant \underline{f}$ do

$x:=\operatorname{opt}\left(f ; f^{\prime} \leq \varepsilon\right)$

if $\nexists x^{\prime} \in P$ such that $x^{\prime}>x$ then $P:=P \cup\{x\}$

$\varepsilon:=\varepsilon-\delta$

end while

Output: Set of Pareto-optimal decision vectors $P$

Figure 1.- Bi-objective $\varepsilon$-constraint Method (for objectives $f$ and f') 


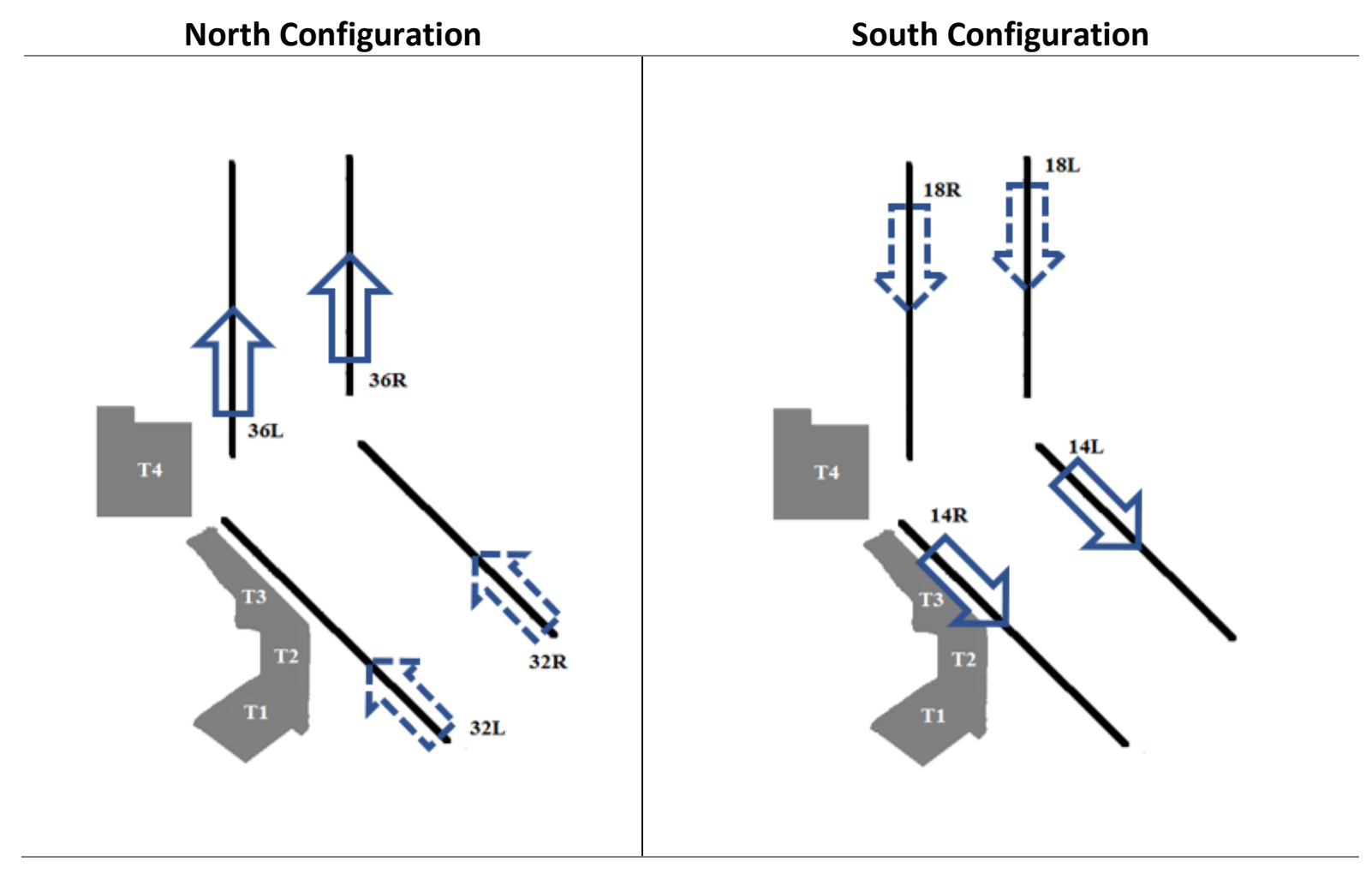

Figure 2. Adolfo Suárez Madrid-Barajas airport - North and South configurations. Solid arrows represent the direction of departures and spotted arrows represent the direction of landings 


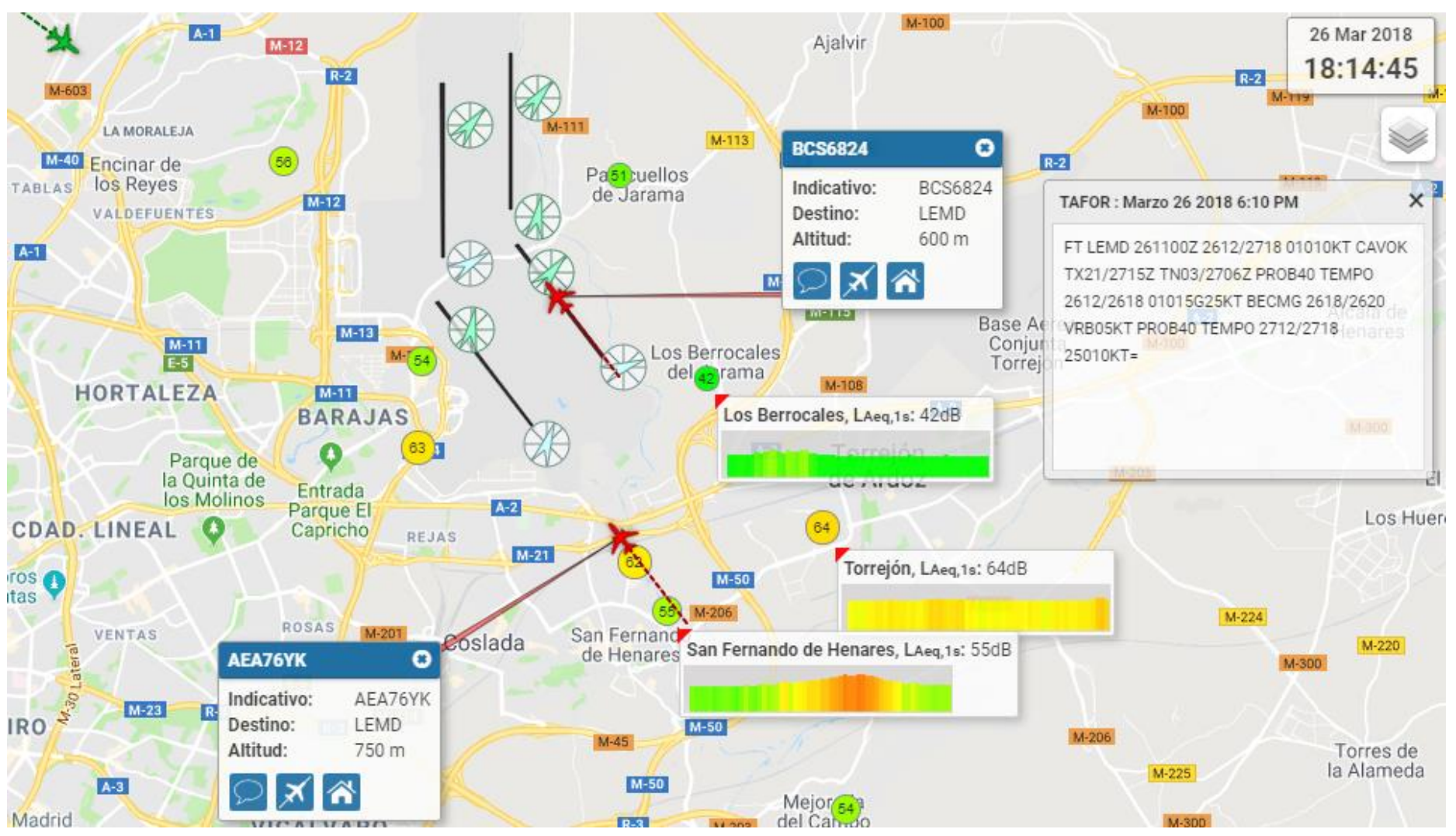

Figure 3. WebTrack screenshot example (WebTrack AENA, 2018) 


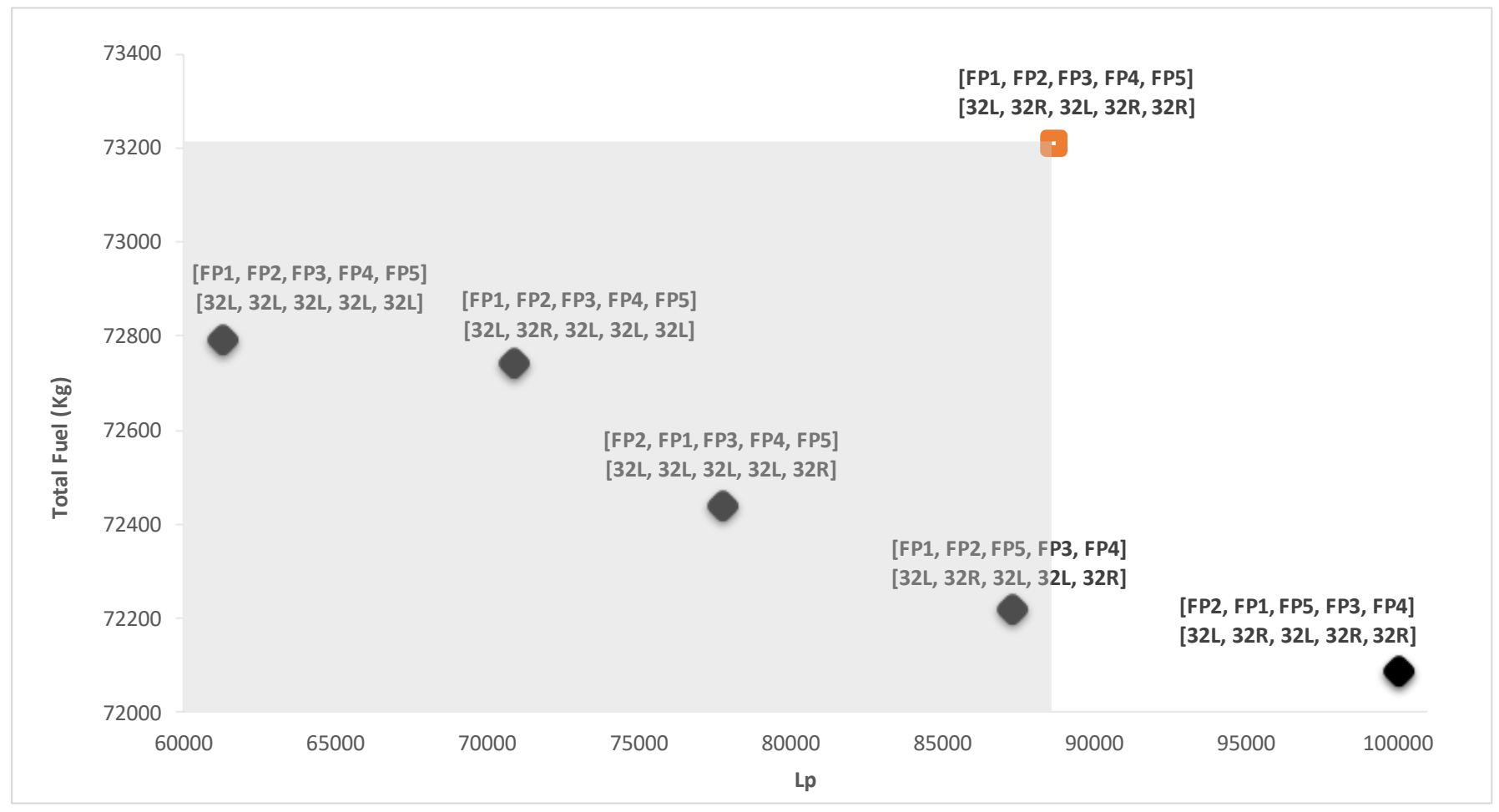

Figure 4. Alternative sequences found by the model for 5 FPs with CPS=2. Diamonds are solutions in the Pareto frontier, and the square point is the real schedule that day. All points in the shadowed area dominate (are better in both cost and noise) than the real schedule operated 


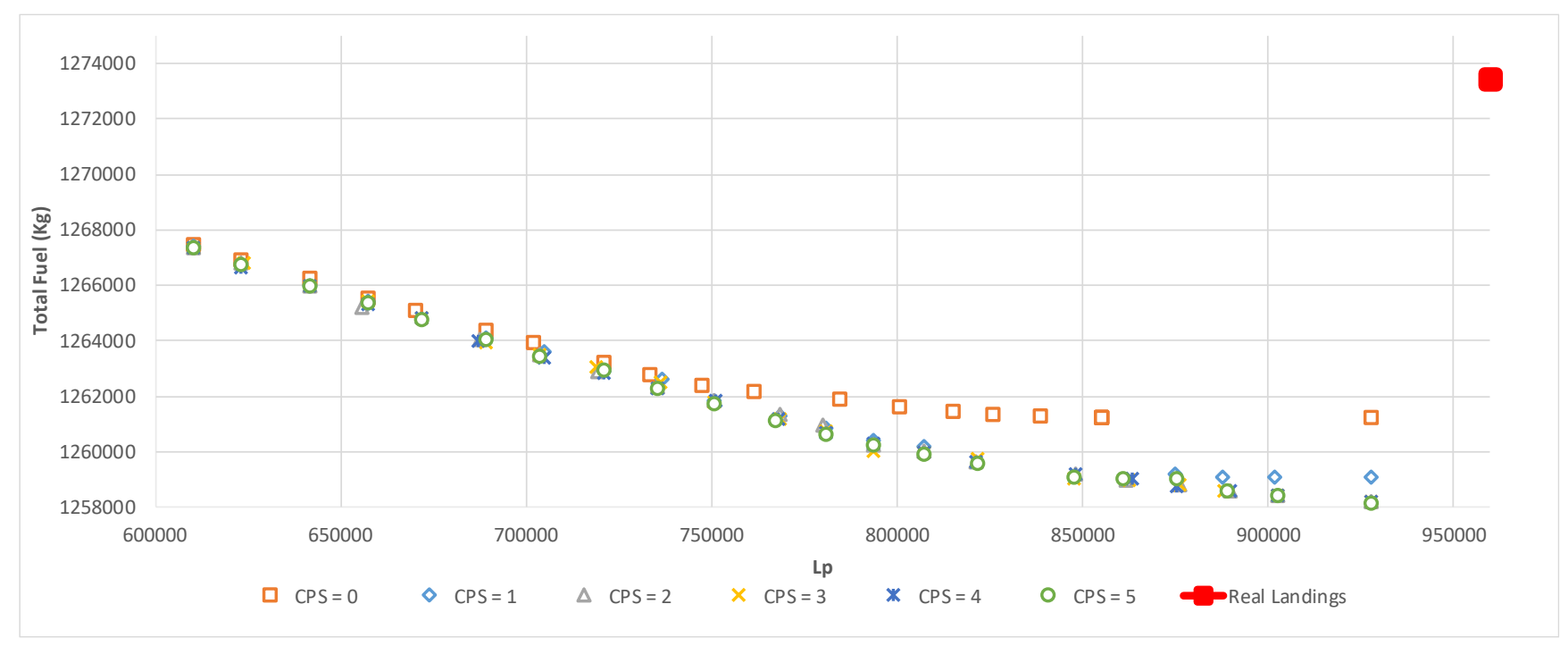

Figure 5. Pareto frontier for 50 flights (corresponding to the Low congestion time frame) with different values of CPS. All solutions found are better than the real schedule operated 


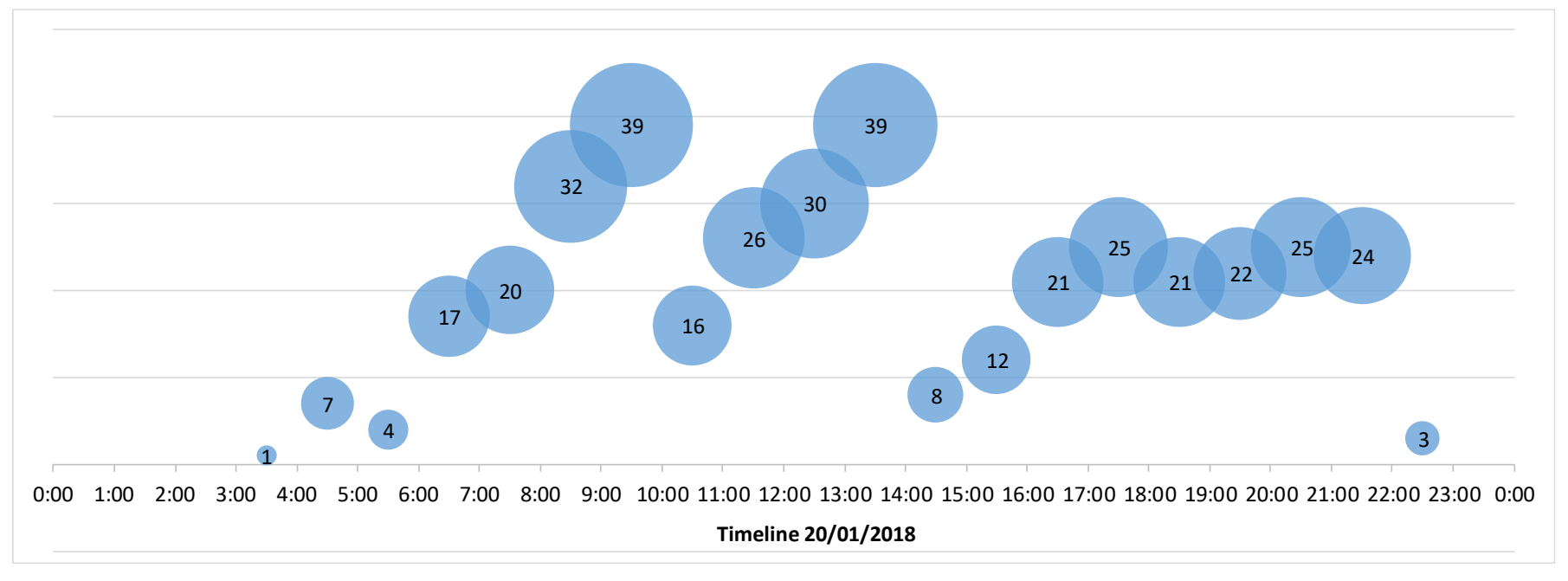

Figure 6. Number of flights landing in every hour slot on the 20th January 2018 in Adolfo Suárez Madrid-Barajas Airport 


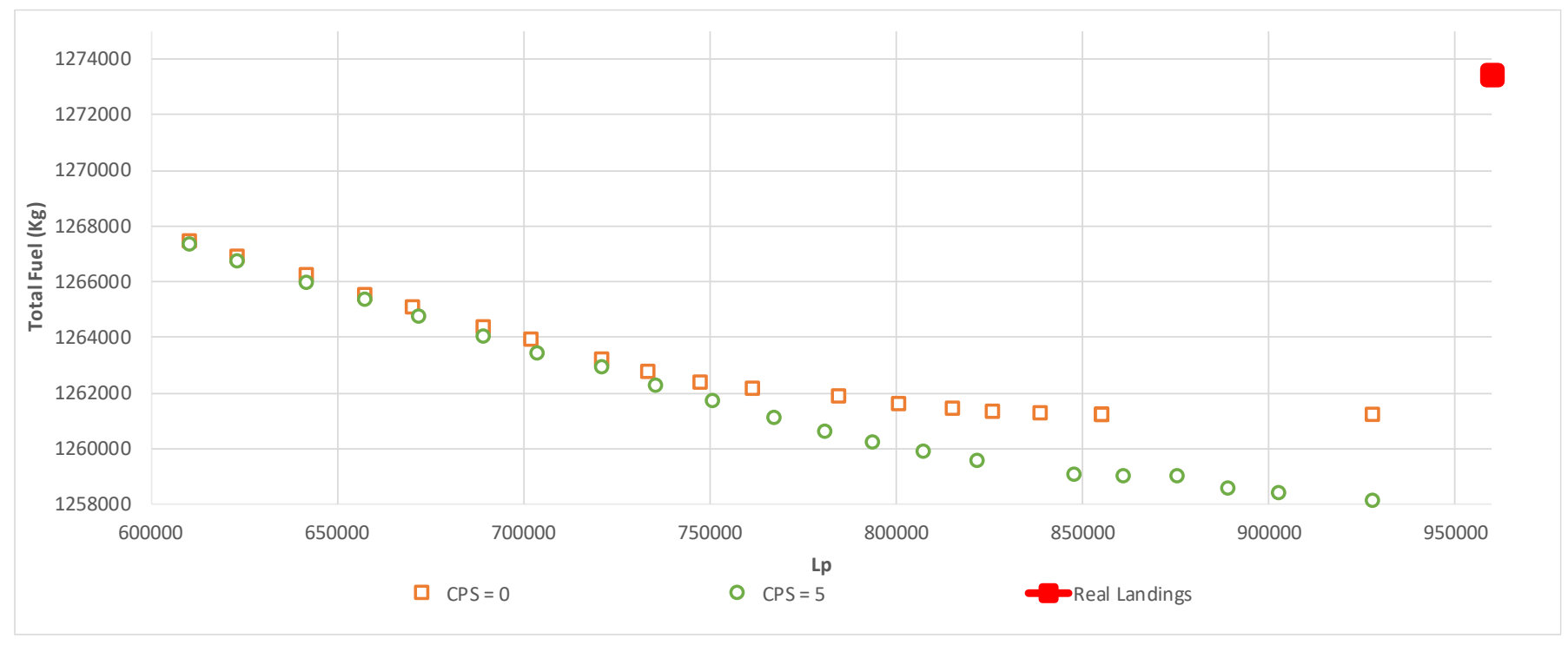

Figure 7. Solutions found for 50 flights landing from 00:00 to 08:00 (Low congestion). The square point represents the real sequence (which is worse than all the solutions found) 


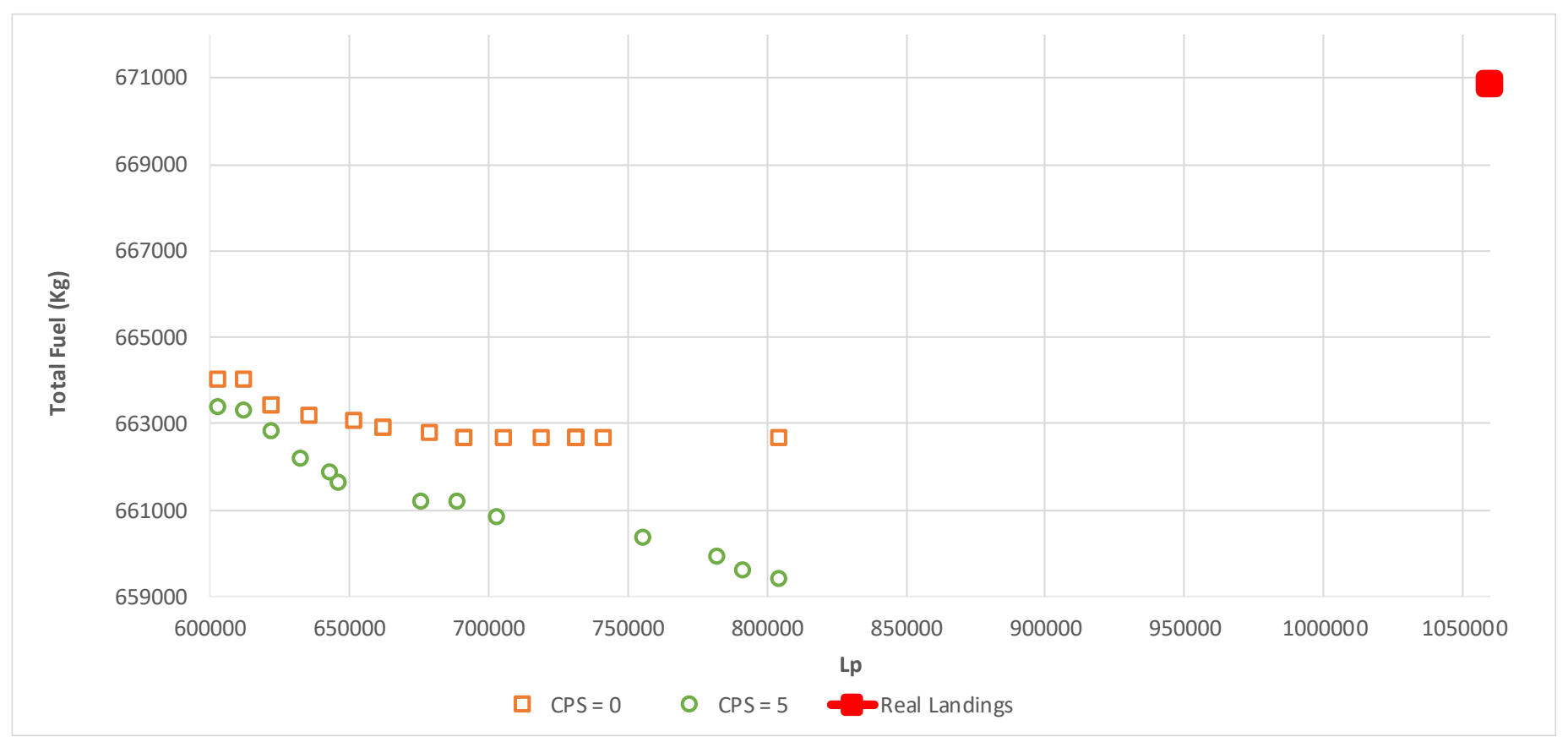

Figure 8. Solutions found for 50 flights landing from 12:00 to 13:30 (High congestion).

The square point represents the real sequence (which is worse than all the solutions found) 


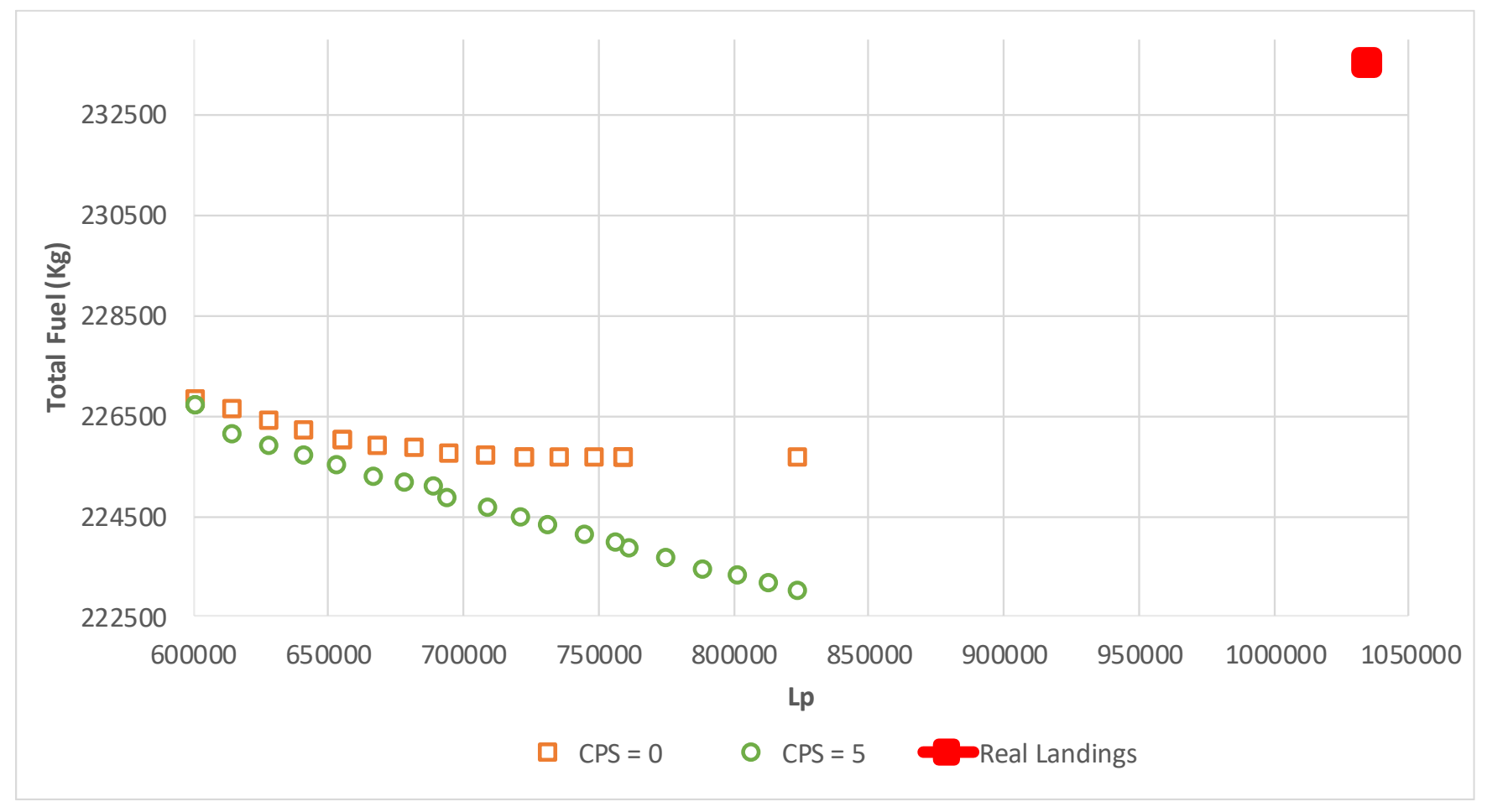

Figure 9. Solutions found for 50 flights landing from 20:10 to 22:10 (Intermediate congestion). The square point represents the real sequence (which is worse than all the solutions found) 


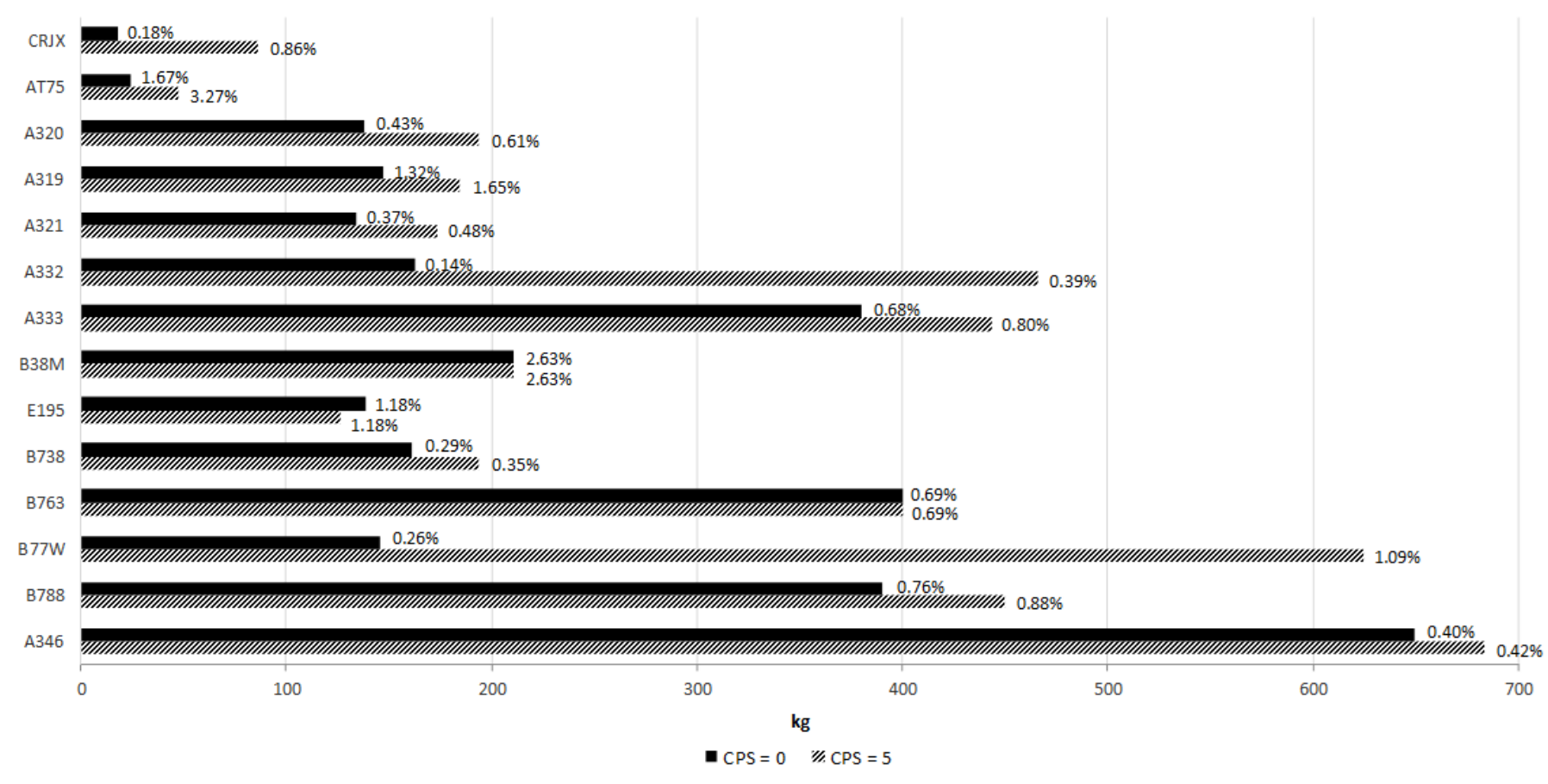

Figure 10. Difference of fuel consumption $(\mathrm{kg})$ between the real solution and the best solution found by minimizing fuel consumption, for two different CPS and per type of airplane (Intermediate congestion time frame flights). For each aircraft type, the percentage of improvement in terms of fuel consumption is shown per CPS. 


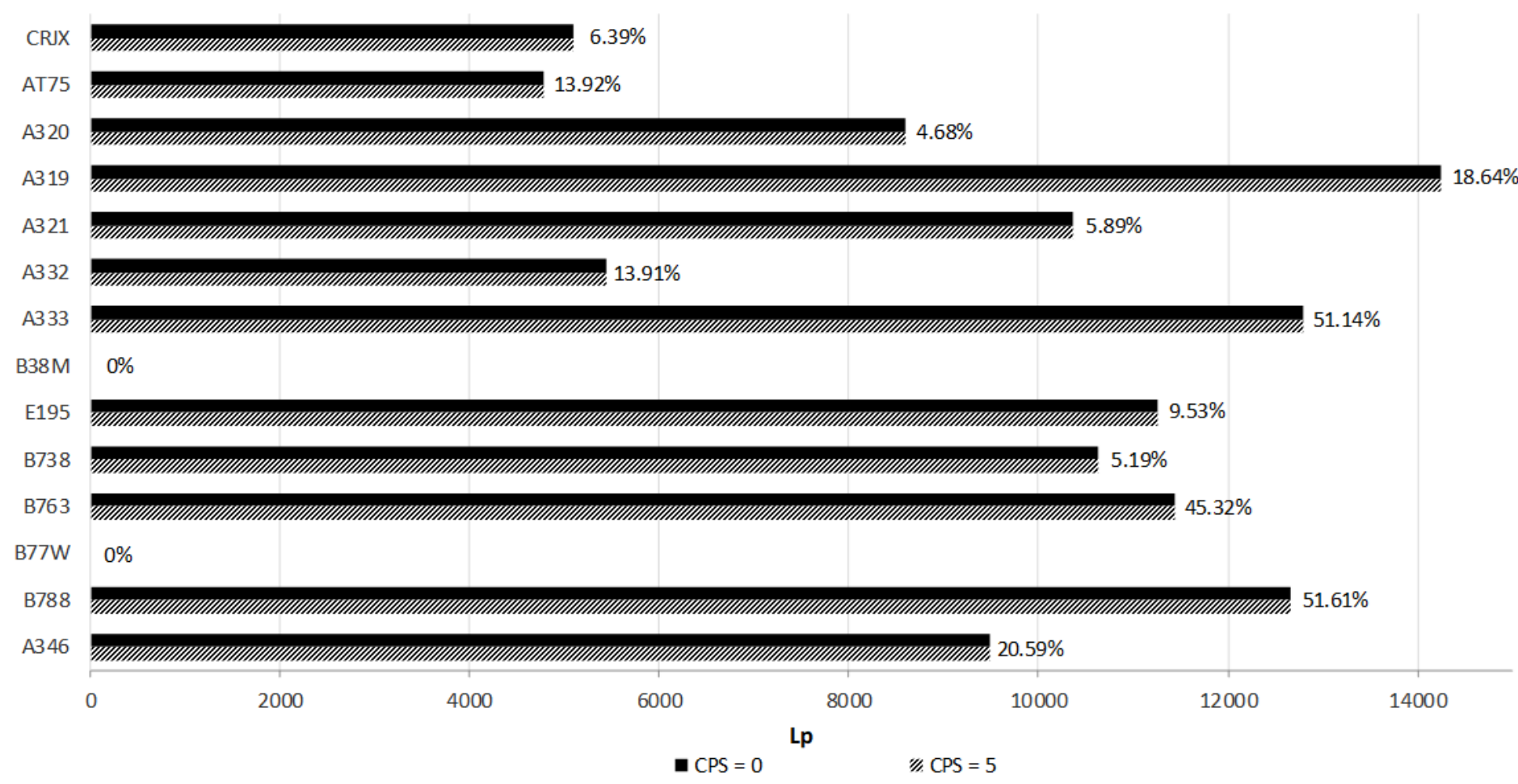

Figure11. Difference in noise level between the real solution and the best solution found minimizing noise, for two different CPS and per type of airplane (Intermediate congestion time frame flights). 
Table 1. Scenario description. Population taken from the Spanish National Institute of Statistics, with reference date January 2018 (INE, 2018). NMTs are grouped by Arrivals/Departures, recording the noise when Adolfo Suarez Madrid-Barajas Airport operates in the North configuration.

\begin{tabular}{cccclr}
\hline NMT & A/D & $\mathbf{L}_{\text {eq }}$ day $(\mathbf{d B})$ & $\mathbf{L}_{\text {eq }}$ night $(\mathbf{d B})$ & Location & Population (2017) \\
\hline 3 & D & 53 & 32 & Dehesa Vieja & 78,203 \\
\hline 4 & D & 54 & 45 & Fuente del Fresno & 1,265 \\
\hline 24 & D & 50 & 23 & Ciudalcampo & 609 \\
\hline 26 & D & 50 & 44 & Club de Campo & 3,500 \\
\hline 27 & D & 58 & 39 & La Granjilla & 500 \\
\hline 2 & D & 53 & 31 & Algete & 15,476 \\
\hline 5 & D & 50 & 44 & Urbanización Santo Domingo Sur & 2,917 \\
\hline 21 & D & 50 & 43 & Urbanización Santo Domingo Norter & 1,877 \\
\hline 25 & D & 53 & 53 & Prado Norte & 114,864 \\
\hline 1 & D & 39 & 38 & La Moraleja & 6,424 \\
\hline 6 & D & 54 & 46 & Fuente el Saz & 46,046 \\
\hline 16 & D & 44 & 22 & Tres Cantos & 8,491 \\
\hline 18 & D & 47 & 39 & El Molar & 23,905 \\
\hline 7 & D & 49 & 39 & Paracuellos & 1,611 \\
\hline 9 & D & 62 & 53 & Belvis & $\mathbf{7 9 8}$ \\
\hline $\mathbf{2 3}$ & A & $\mathbf{4 8}$ & $\mathbf{4 2}$ & Los Berrocales & $\mathbf{2 0 , 5 4 9}$ \\
\hline $\mathbf{1 2}$ & A & $\mathbf{3 8}$ & $\mathbf{2 9}$ & Alameda de Osuna & $\mathbf{4 6 , 8 7 6}$ \\
\hline $\mathbf{1 3}$ & A & $\mathbf{4 9}$ & $\mathbf{4 3}$ & Barajas & $\mathbf{2 2 , 9 4 8}$ \\
\hline $\mathbf{8}$ & A & $\mathbf{5 9}$ & $\mathbf{4 8}$ & Mejorada & $\mathbf{3 9 , 6 8 1}$ \\
\hline $\mathbf{1 0}$ & A & $\mathbf{6 3}$ & $\mathbf{5 2}$ & San Fernando de Henares & $\mathbf{8 3 , 0 1 1}$ \\
\hline $\mathbf{1 1}$ & A & $\mathbf{6 6}$ & $\mathbf{5 5}$ & Coslada & $\mathbf{1 2 8 , 0 1 3}$ \\
\hline $\mathbf{2 0}$ & A & $\mathbf{4 9}$ & $\mathbf{4 4}$ & Torrejón &
\end{tabular}


Table 2. Average peak noise $(d B)$ in the three NMTs, when landing on the two possible runways (32R and $32 L)$

\begin{tabular}{|c|c|c|c|c|c|c|}
\hline \multirow{2}{*}{ Aircraft } & \multicolumn{2}{|c|}{ Average Noise (dB)-NMT 10} & \multicolumn{2}{|c|}{ Average Noise (dB)-NMT 11} & \multicolumn{2}{|c|}{ Average Noise (dB)-NMT 20} \\
\hline & $32 R$ & $32 L$ & $32 R$ & $32 L$ & $32 R$ & $32 L$ \\
\hline A319 & 55 & 74 & 55 & 76 & 55 & 54 \\
\hline A320 & 57 & 74 & 57 & 77 & 56 & 56 \\
\hline A321 & 55 & 74 & 56 & 77 & 56 & 55 \\
\hline A332 & 58 & 74 & 59 & 77 & 58 & 55 \\
\hline A333 & 55 & 74 & 55 & 77 & 57 & 55 \\
\hline$A 343$ & 55 & 78 & 55 & 81 & 59 & 56 \\
\hline A346 & 56 & 79 & 56 & 81 & 59 & 56 \\
\hline$A T 75$ & 53 & 72 & 53 & 75 & 57 & 53 \\
\hline$A T 76$ & 55 & 71 & 56 & 74 & 56 & 56 \\
\hline B738 & 56 & 75 & 57 & 77 & 56 & 55 \\
\hline B763 & 56 & 75 & 57 & 78 & 59 & 56 \\
\hline B764 & 56 & 78 & 57 & 81 & 59 & 56 \\
\hline$B 77 W$ & 56 & 75 & 57 & 78 & 59 & 56 \\
\hline B788 & 55 & 74 & 56 & 77 & 56 & 53 \\
\hline B789 & 55 & 75 & 56 & 77 & 57 & 52 \\
\hline CRJ2 & 53 & 73 & 54 & 75 & 54 & 53 \\
\hline CRJX & 55 & 73 & 55 & 75 & 54 & 54 \\
\hline$E 190$ & 58 & 71 & 58 & 74 & 56 & 56 \\
\hline E195 & 58 & 73 & 58 & 76 & 56 & 56 \\
\hline
\end{tabular}


Table 3. Flight plans data for simplified real example (STD-Scheduled Departure from origin airport; fuel data taken from ICAO, 2016)

\begin{tabular}{ccccccccc}
\hline ID & Callsign & Origin & Aircraft & STD & $\begin{array}{c}\text { Tflight } \\
\text { (min) }\end{array}$ & $\begin{array}{c}\text { Runway } \\
\text { used }\end{array}$ & WTC & $\begin{array}{c}\text { Fuel } \\
\text { (kg/s) }\end{array}$ \\
\hline FP1 & UX9161 & $\begin{array}{c}\text { Las } \\
\text { Palmas } \\
\text { (LPA) }\end{array}$ & B738 & $\begin{array}{c}20-1-18 \\
10: 00\end{array}$ & 152 & $32 \mathrm{~L}$ & $\mathrm{M}$ & 0.694 \\
\hline FP2 & UX4042 & $\begin{array}{c}\text { Alicante } \\
\text { (ALC) }\end{array}$ & AT75 & $\begin{array}{c}20-1-18 \\
11: 30\end{array}$ & 63 & $32 \mathrm{R}$ & $\mathrm{M}$ & 0.172 \\
\hline FP3 & UX9047 & $\begin{array}{c}\text { Tenerife } \\
\text { (TFN) }\end{array}$ & B738 & $\begin{array}{c}20-1-18 \\
10: 00\end{array}$ & 154 & $32 \mathrm{~L}$ & $\mathrm{M}$ & 0.694 \\
\hline FP4 & IB8711 & $\begin{array}{c}\text { Lyon } \\
\text { (LYS) }\end{array}$ & CRJX & $\begin{array}{c}20-1-18 \\
11: 10\end{array}$ & 85 & $32 \mathrm{R}$ & $\mathrm{M}$ & 0.444 \\
\hline FP5 & QR149 & $\begin{array}{c}\text { Doha } \\
\text { (DOH) }\end{array}$ & B77W & $\begin{array}{c}20-1-18 \\
05: 00\end{array}$ & 457 & $32 \mathrm{R}$ & $\mathrm{H}$ & 2.083 \\
\hline
\end{tabular}


Table 4. Comparison of \% improvement compared with real solution for the 3 scenarios (Low, Intermediate and High congestion) and two different values of CPS

\section{Low congestion Intermediate congestion High congestion}

Fuel

\begin{tabular}{cccccc}
\hline $\mathrm{CPS}=0$ & $\mathrm{CPS}=5$ & $\mathrm{CPS}=0$ & $\mathrm{CPS}=5$ & $\mathrm{CPS}=0$ & $\mathrm{CPS}=5$ \\
\hline $0.95 \%$ & $1.20 \%$ & $3.37 \%$ & $4.50 \%$ & $1.22 \%$ & $1.71 \%$ \\
$36.44 \%$ & $36.44 \%$ & $41.91 \%$ & $41.91 \%$ & $43.12 \%$ & $43.12 \%$
\end{tabular}

Noise impact

$41.91 \%$

$41.91 \%$

$43.12 \%$

$3.12 \%$ 